\title{
EL FRAUDE A LA LEY FISCAL EN EL DERECHO TRIBUTARIO URUGUAYO
}

\author{
FRAUD TO FISCAL LAW IN URUGUAYAN TAX LAW
}

\section{A FRAUDE À LEI FISCAL NO DIREITO TRIBUTÁRIO URUGUAIO}

Jorge W. Ibiñete*

RESUMEN. Se aborda el fraude a la ley en el derecho tributario, principalmente como posibilidad de alcanzar con el hecho generador actos y negocios que sin estar nominados en la norma fiscal, tengan igual sustrato material que el previsto en la misma.-Se examina el concepto de fraude a la ley en el derecho privado y sus elementos estructurales, así como sus diferencias con otras figuras que también incluyen al fraude, como la acción pauliana y el disregard. Se estudia la evolución del tratamiento de los actos y negocios en nuestro Derecho Tributario, así como las diferencias con mecanismos para el control de los actos fraudulentos, como la interpretación económica y la interpretación teleológica, que extienden por analogía el hecho generador, y las normas antielusivas genéricas, que reconducen al acto o negocio a una forma gravada. Se evalúa la admisibilidad de un concepto de fraude a la ley propio del derecho tributario, que sobre la base de una interpretación finalista, postula un concepto de ilicitud basado en la violación de principios del derecho tributario. Finalmente se analiza el tratamiento en el derecho tributario material de los actos o negocios que respetando la letra de la ley, pero no su sentido, tratan de evitar el hecho generador.

PALABRAS CLAVE. Fraude a la ley. Evasión. Elusión. Integración analógica. Interpretación extensiva.

ABSTRACT. Fraud against tax laws is addressed, mainly as a possibility to achieve, by means of the taxable event, certain acts and transactions that, without being set forth under such tax laws, have the same material foundation as provided for therein. The concept of fraud against the law within the scope of private law as well as structural elements thereof are examined, in addition to its differences in comparison to other concepts that also include fraud, such as fraudulent conveyance and disregard. The evolution of the handling of acts and transactions in our tax law is studied, as well as the differences with

\footnotetext{
* Doctor en Derecho y Ciencias Sociales de la Universidad de la República; ex asesor letrado de la Dirección General Impositiva. Correo electrónico: jorge.ibiete@gmail.com.
} 
the mechanisms to control fraudulent acts, such as economic interpretation and teleological interpretation, which extend, by analogy, the taxable event, and generic anti-avoidance regulations, which redirect such act or transaction to a taxed form. The admissibility of a concept of tax law fraud is assessed, which, based on a conclusive interpretation, proposes a concept of wrongfulness based on the violation of tax law principles. Finally, the use of substantive tax law towards acts or transactions compliant with the law's wording, but not its meaning, that seek to avoid any taxable event is reviewed.

KEYWORDS. Legal Fraud. Evasion. Avoidance. Analogical integration. Extensive interpretation.

RESUMO. A fraude à lei no direito tributário é abordada, principalmente como uma possibilidade de alcançar, com o fato gerador, ações e negócios que, sem serem indicados na norma fiscal, possuem o mesmo substrato material que o previsto nela. O conceito de fraude contra a lei no direito privado e seus elementos estruturais sãoexaminados, bem como suas diferenças com outras figuras que também incluem fraude, como a ação pauliana e a desconsideração. São estudadas a evolução do tratamento dos atos e negócios em nosso Direito Tributário, bem como as diferenças com mecanismos de controle de atos fraudulentos, como a interpretação econômica e a interpretação teleológica, que estendem por analogia o fato gerador e as regras genéricas anti-evasão que redirecionam o ato ou negócio para um formulário tributado. É avaliada a admissibilidade de um conceito de fraude contra a lei do direito tributário que, com base em uma interpretação final, postula um conceito de ilegalidade com base na violação dos princípios do direito tributário. Por fim, é analisado o tratamento na lei tributária relevante de atos ou negócios que, respeitando a letra da lei, mas não seu significado, tente evitar que o fato gerador seja analisado.

PALAVRAS CHAVE. Fraude à lei. Evasão. Circunvenção. Integração analógica. Interpretação extensa.

\section{INTRODUCCIÓN.}

1. El fraude a la ley fiscal se suele referir, principalmente, a la posibilidad de alcanzar con los tributos actos y negocios no contemplados en la norma, pero que tienen igual sustrato material que los previstos en la misma. 
2. La complejidad del tema deriva, no solo de que el término fraude se utiliza por el legislador con distintos significados y alcances, sino también de la ausencia de una definición legal, así como de la influencia de doctrina y jurisprudencia de países del common law (aspecto destacado por BLENGIO, 1985, pp. 43-44), o que tienen normas que permiten la extensión analógica del hecho generador o la reconducción del acto o negocio verdadero y lícito a formas gravadas.

3. Tampoco puede ignorarse la presión de las administraciones fiscales para forzar los límites de la tipicidad, ni los esfuerzos de la doctrina para construir un concepto de esta figura propio del derecho tributario, tensando dichos límites, así como los de la autonomía calificadora del derecho tributario.

4. En este tema también subyace una cuestión ideológica, porque, como expresa TAVEIRA (2008), la opción de legalidad y tipicidad se corresponde con un ideario de orientación liberal, mientras que la flexibilización de la legalidad redunda en beneficio de los intereses del Estado (p. 182).

\section{EL FRAUDE A LA LEY FISCAL.}

5. Concepto de fraude a la ley en el derecho privado.

5.1 El fraude a la ley es una figura originada en el derecho romano, que se elabora en el derecho privado, extendiéndose luego a otras ramas del Derecho, circunstancia que impone tomar a esa elaboración como punto de partida de nuestro análisis.

5.2 En nuestro país las definiciones de la doctrina del derecho privado son coincidentes en el sentido de que el fraude a la ley es un negocio o combinación de actos, hechos o negocios verdaderos y formalmente lícitos, que violan indirectamente una prohibición legal, respetando la letra de la ley, pero no su sentido.

Para SÁNCHEZ (1965), “....consiste en la realización de actos, hechos o negocios en sí mismos lícitos, pero que tienden a obtener, en forma indirecta, un resultado prohibido por la norma; a diferencia del negocio simulado, se trata de un negocio real, cuya ilicitud deriva únicamente de contradecir el fin de la ley" (pp. 48-49).

Para BLENGIO (1985), es “...un negocio (o conjunto de ellos), formalmente lícito articulado de tal modo que produce un resultado (el mismo o semejante según sea o no admisible la analogía) vedado por la ley" (p. 56).

Los autores señalan que se viola el espíritu o el fin de la norma, porque si el negocio choca directamente contra la letra, estaríamos frente a un negocio contra legem, y no in fraudem legis. Por esa razón hay quienes sostienen que el fraude a la ley carece de autonomía, porque si se trata de un comportamiento que, sin chocar con la letra de la ley viola sin embargo su espíritu, está claro que la cuestión se resuelve con una correcta determinación 
del alcance de la misma, que no depende exclusivamente de su letra (BLENGIO, 1985, pp. 45-46).

5.3 El fraude a la ley se vincula con los negocios fiduciarios e indirectos, en tanto ambos persiguen un fin distinto al normal, que los hace aptos para obtener un resultado prohibido por la ley (GAMARRA, 1999, pp. 209), aunque también puede resultar de una combinación de hechos, actos o negocios. Por ejemplo, propietario que habita casa propia y se muda a un hotel o a una casa alquilada, para desalojar otra finca de su propiedad y habitarla personalmente, eludiendo el régimen -entonces existente- de estabilización en favor de los arrendatarios (SÁNCHEZ, 1965, pp. 48-49).

5.4 Quedan fuera de esta definición los casos de simulación, no solo porque el negocio simulado no es verdadero, sino porque el encubierto viola directamente la ley, aunque en forma velada (BLENGIO, 1985, p. 48). No obstante, las diferencias son menos sustanciales de lo que aparentan, porque "Bastaría con concebir al fraus legis, como una modalidad de violación de la norma caracterizada fundamentalmente por la circunstancia de haber sido artificiosamente articulada, para que volviera a absorber en su seno a los negocios simulados" (BLENGIO, 1985, p. 48). En este sentido amplio, menciona GAMARRA (1999) el fraude a la ley, para referirse a la falsedad de la causa o la interposición ficticia, para violar normas prohibitivas, que constituyen hipótesis de simulación (pp. 80, 81 y 90).

6. La ilicitud en el fraude a la ley y diferencias con el fraude pauliano y el disregard. 6.1 A diferencia de otras legislaciones, como la italiana, española, brasileña y argentina, nuestro derecho privado, si bien menciona al fraude a la ley en el art. 189 inc. $1^{\circ}$ de la ley n. ${ }^{\circ} 16.060$ de 04/09/1989, ley de Sociedades Comerciales (LSC), no contiene una definición de esa figura, ni disposiciones que establezcan la nulidad de lo hecho en contra de las normas prohibitivas, aun cuando se utilicen medios o formas distintas a las previstas en las mismas ; o que el motivo o finalidad de evitar dichas normas determine la nulidad de la causa del acto o negocio, aspectos que analizaremos más adelante.

No obstante, el fraude a la ley se elabora en la doctrina como respuesta al comportamiento que busca eludir las prohibiciones y mandatos legales por vías oblicuas, sobre la base del principio fraus omnia corrumpit, cuya existencia es confirmada por normas que buscan atacar un determinado resultado con prescindencia de los medios empleados (BLENGIO, 1985 , pp. 43 y 57 y ss.).

6.2 Nuestra legislación se refiere al fraude, tanto para aludir a la conducta engañosa, como al resultado de esa conducta, consistente en la violación de una norma prohibitiva (fraude a la ley) o de un derecho subjetivo de terceros.

Observa BLENGIO (1985) que la mayor parte de la doctrina mantiene separado el fraude pauliano del negocio en fraude a la ley, citando como diferencias que el fraude a la ley impide la aplicación de la norma, mientras que en el fraus creditoris importa, no la elusión 
de la norma, sino el daño al derecho de los acreedores, además que no puede considerarse al ordenamiento jurídico como un tercero, en el sentido que se le emplea en el fraude pauliano (nota 117 en pp. 58-59). HESSDÖRFER (2004), en cambio, menciona como ejemplos de fraude a la ley a la acción pauliana y el disregard (p. 632).

Estas figuras también difieren en cuanto a la exigencia del elemento subjetivo (infra nral. 7.), así como con respecto a sus consecuencias, porque los actos o negocios que violan la ley prohibitiva son nulos, salvo que la misma disponga lo contrario, como lo establece el art. $8^{\circ}$ Código Civil (CC), mientras que los que violan un derecho subjetivo no son nulos, sino inoponibles al tercero afectado por el fraude, como se prevé en los casos de la acción pauliana y el disregard. Si bien estas normas llevan implícita la prohibición de la conducta contraria al mandato legal, su incumplimiento no causa nulidad, en virtud de que la violación del derecho ajeno es un acto ilícito que tiene efectos sancionatorios y resarcitorios, mientras que el acto nulo no produce efecto alguno (GAMARRA, 1974, pp. 77 y ss.).

6.3 La doctrina, en general, señala que el fraude a la ley se verifica por la violación oblicua de normas preceptivas en sentido amplio, tanto las prohibitivas cuanto las que ordenan una determinada conducta (imperativas) (BLENGIO, 1985, p. 60 y 62; TAVEIRA, 2008, p. 296 y ss.). A este criterio amplio responde la definición que acoge BLANCO (2008): “...la colocación del sujeto en una determinada posición, no aparente sino real, que le significa la obtención de determinadas ventajas, o la obtención de determinados provechos, pero eludiendo la aplicación de algunas o alguna norma jurídica” (p. 44).

Es claro que otro tipo de normas, cuyo cumplimiento no puede ser exigido, como las ordenativas , así como las supletorias, no pueden ser violadas, al igual que las que establecen imperativos hipotéticos, mientras no se verifiquen los supuestos establecidos en la misma para la efectividad de su mandato o prohibición.

6.4 Sin embargo, no todas las normas preceptivas son pasibles de fraude a la ley, porque aquellas que obligan a una determinada acción, se violan por la omisión del cumplimiento del mandato legal, no quedando espacio para una violación indirecta de la norma. En todo caso, lo que puede violarse oblicuamente es el derecho subjetivo en favor de terceros que puede emerger de dicha norma, lo que nos coloca fuera del ámbito del fraude a la ley (supra nral. 6.2).

6.5 Como surge del art. 24 Código Tributario (CT), las normas que definen el hecho generador establecen un imperativo hipotético, desde que obligan si se verifican las situaciones y actos previstos en las mismas (no similares), por lo que no resulta posible el fraude a la ley. En tal sentido, en la conclusión del Informe de la Comisión para el estudio y propuestas de medidas para la Reforma de la Ley General Tributaria (LGT) de España, se afirma que “...este mecanismo (el fraude de ley) no resulta, en principio y con carácter general, aplicable a un ámbito como el tributario, que lejos de constituir un orden de 
prohibiciones se articula en mandatos positivos de pagar una cantidad de dinero a todo el que realice un determinado hecho" (TAVEIRA, 2008, pp. 304-305).

Tampoco las normas tributarias obligan a estructurar los negocios de forma que sean gravados por tributos o que lo sean en la mayor medida posible, lo que permitiría considerar verificado un hecho generador que en realidad no se configuró (FAGET, 2004, p. 437), o lo hizo en una menor cuantía.

En cuanto a otras normas tributarias, como las que determinan exoneraciones o la cuantía de los tributos, lo que puede eludirse indirectamente, total o parcialmente, es la obligación tributaria, y no la norma tributaria, que se viola directamente.

No obstante, en el capítulo III. analizaremos cuál es la respuesta del derecho tributario frente a los actos realizados con intención elusiva.

7. El aspecto subjetivo en el fraude a la ley.

7.1 Consistiendo el fraude a la ley en una violación indirecta de ciertas normas, es claro que la intención de las partes no puede tener relevancia alguna (BLENGIO, 1985, pp. 46 y 57 y TAVEIRA, 2008, pp. 295-296), a diferencia de lo que ocurre cuando se trata de la violación de un derecho subjetivo, aunque dicha intención, o su ausencia, son relevantes a otros efectos, como en materia de infracciones. FAGET (1993), por el contrario, afirma que "es el móvil de las partes lo que otorga a un negocio su carácter fraudulento"; y que "la circunstancia de que exista un «business purpose» hace descartar la posibilidad de estar frente a una evasión...", (pp. 377 y 384-385).

El fraude se consuma por la violación de la norma, y no por la intención de violarla; la intención de pagar menos impuestos no es en sí misma ilícita (GARCÍA, 2008, p. 12), ni es un motivo que habilite para extender la norma tributaria a hipótesis no previstas, porque ello importaría aplicar la analogía, so pretexto del fraude (BLENGIO, 1985, p. 53).

7.2.1 Por otra parte, el fin ulterior que persigue el resultado indirecto, pertenece a la zona de los motivos, que son jurídicamente irrelevantes (GAMARRA, 1972, pp. 22 y ss. y 1999, pp. 192-193 y 207-209).

En su obra de 2009, GAMARRA modificó la opinión antes citada, afirmando que la causa no es la función económica social (causa abstracta), sino la función económica individual (causa concreta), que identifica con el motivo relevante o interés, lo que haría caer la separación entre causa y motivo (pp. 295-307).

7.2.2 Esta nueva doctrina ha sido fuertemente cuestionada por CARNELLI (2012), sosteniendo que la misma se basa en autores que no están constreñidos por una definición legal como la del art. 1287 CC (que define la causa en atención al tipo contractual); que en realidad la función económica individual (concreta), no hace caer la separación entre causa y motivos, porque la función del contrato responde a su estructura, que es la que 
determina sus efectos, y no a la inversa; y porque los motivos, cuando son relevantes, son la causa y se sitúan en la construcción válida del contrato (pp. 419 y ss.).

7.3 Tampoco la causa de un contrato nominado puede ser ilícita, como dice el art. 1288 del CC, porque la causa (abstracta) de un contrato nominado está establecida en la ley (GAMARRA, 1972, p. 24). La que sí puede ser ilícita es la conducta comprometida para obtener una determinada utilidad, lo que tiene por consecuencia la nulidad absoluta del contrato por ilicitud del objeto (CARNELLI, 2012, p. 431).

7.4 Por las mismas razones expuestas anteriormente, tampoco es relevante a estos efectos la existencia de un verdadero propósito de negocios, porque el mismo no permite convalidar la ilicitud, si es que se viola una norma prohibitiva; ni la ausencia de dicho propósito determina, por sí sola, la ilicitud del negocio. No obstante, el propósito de negocios puede resultar relevante en el campo infraccional, así como para apreciar la adecuación de la forma o la utilización de determinadas modalidades negociales, así como la ausencia de dicho propósito puede ser un elemento revelador de la simulación por inexistencia o falsedad de la causa. BORDOLLI (1994), en cambio, considera que el "propósito de negocios" solo posee relevancia a los efectos del derecho privado (p. 31).

\section{TRATAMIENTO DE LOS ACTOS O NEGOCIOS DEL DERECHO PRIVADO, EN EL DERECHO TRIBUTARIO.}

\section{Régimen anterior al Código Tributario.}

8.1 Con anterioridad a la vigencia del CT, que comenzó a regir el 1\%/01/1975, según art. $2^{\circ}$ del DL n ${ }^{\circ} 14.306$ de 29/11/1974, se consideraba que el Fisco no podía desconocer las formas adoptadas por el contribuyente -salvo en el caso de la venta simulada para defraudar el Impuesto a las Herencias, cuya nulidad debía reclamar el fiscal ante la Justicia (art. 50 de la ley $\mathrm{n}^{\circ} 13.695$ de 24/10/1968)-, ni los precios consignados en las facturas efectuadas entre empresas económicamente vinculadas, aunque el art. 375, nral. 3), lit. g) de la ley $\mathrm{n}^{\circ} 12.804$ de 30/11/1960 había introducido una brecha en ese régimen, al establecer como una presunción de la intención de defraudar, "Hacer valer formas jurídicas manifiestamente inapropiadas a la realidad de los hechos gravados".

Como consecuencia de este sistema, se dictaron normas sobre la base del concepto de conjunto económico, para combatir casos puntuales de evasión o para preservar la garantía de cobro de los tributos de la seguridad social.

Las normas referidas son: Impuesto a las Ganancias Elevadas (IGE), art. 31 de la ley n ${ }^{\circ}$ 10.597 de 28/12/1944; Impuesto a la Renta de las Personas Físicas (IRPF) -ley 12.804-, categoría Agropecuaria, art. 26 de la ley $n^{\circ} 12.804$ cit., en la redacción dada por el art. $1^{\circ}$ de la ley $n^{\circ} 13.319$ de 28/12/1964; Impuesto a las Ventas y Transacciones (IVT), art. 83 de la ley $n^{\circ} 12.804$ cit.; y en materia de tributos de la seguridad social, art. 32 de la ley $n^{\circ}$ 


\subsection{6 de $02 / 12 / 1965$.}

En el caso de las normas para combatir la evasión, estas leyes utilizaban el conjunto económico con distintas finalidades: para determinar el IGE en la forma establecida por la ley, que gravaba las utilidades de la empresa con independencia de su forma jurídica; y para impedir que mediante la interposición ficticia de empresas jurídicamente independientes, pero vinculadas económicamente, se subfacturara el IVT, o que actividades agropecuarias integrantes del ciclo industrial se liquidaran aplicando el régimen más benigno de la Categoría Agropecuaria del IRPF.

En el caso de las contribuciones de la seguridad social, se buscaba preservar la garantía de cobro de dichos tributos, evitando que el desdoblamiento de capitales de un mismo conjunto económico pudiera disminuir o eliminar su solvencia.

8.2 Si el ordenamiento entonces vigente no permitía desconocer las formas jurídicas inadecuadas (salvo la excepción ya mencionada del Impuesto de Herencias, que requería la intervención de la Justicia), menos aún podía admitir el desconocimiento de negocios verdaderos y lícitos, a pesar del antecedente jurisprudencial que referiremos más adelante (infra nral. 10.3).

9. Régimen del Código Tributario.

9.1 A la entrada en vigencia del CT, estaban derogados todos los impuestos cuya evasión se trataba de evitar con las normas especiales antes citadas, manteniéndose vigente solo la norma sobre conjunto económico de la ley $n^{\circ} 13.426$ cit., hasta su sustitución por el régimen general del art. 20 BIS CT, incorporado por el art. 175 de la ley $n^{\circ} 19.438$ de 14/10/ 2016.

El CT modificó la situación anterior, al consagrar en su art. $6^{\circ}$ el principio de la prevalencia de la realidad para la interpretación del hecho generador y la calificación jurídica de las situaciones y actos, facultando al intérprete para desestimar -en ciertos casos- las formas jurídicas inadecuadas a la realidad, sin previa intervención de la Justicia.

En materia de interpretación, este principio se aplica en los casos en que la norma relativa al hecho generador se refiera a situaciones definidas por otras ramas jurídicas, sin remitirse ni apartarse de dichas definiciones. En materia de calificación, la realidad debe prevalecer cuando existe inadecuación de la forma y el hecho generador haya sido definido atendiendo a la realidad y no a la forma jurídica, distinción que, al igual que el art. 24 del mismo Código, se basa en la existencia de hechos generadores formales y sustanciales. Ambos procesos también tienen diferentes alcances, porque la interpretación tiene por objeto verificar si el hecho generador se configuró, mientras que la calificación también abarca otros elementos del acto o negocio, como los sujetos y la cuantía.

La realidad a la que se refiere la norma no es la del mundo de los hechos de existencia real, que sí interesa cuando se están elaborando las normas, sino que los juristas operan 
con la realidad llevada a la norma, donde el proceso interpretativo es exclusivamente jurídico, aspecto en el que coinciden GONZÁLEZ (1997), pp. 214-215, 231 y 238; TAVEIRA (2008), pp. 62 y 73; BLANCO, (2008), pp. 45-49 y (2012), pp. 101 y ss.; y DE BARROS. (2014), pp. 84-87.

9.2 Siendo la finalidad de este principio la recta interpretación de las normas relativas al hecho generador y que la ley tributaria se aplique de acuerdo con su verdadero significado, va de suyo que su aplicación es preceptiva (VALDÉS et al., 2002, pp. 180-183; BORDOLLI, 1994, pp. 15-17 y 21-23), aunque no exista fraude, sea que beneficie o perjudique al Fisco, pudiendo ser invocado por cualquiera de las partes en la relación jurídica tributaria (FERRARI \& GUTIÉRREZ, 2011, pp. 115-118 y autores allí citados) y debiendo aplicarse en su integridad, lo que impide invocarlo solo para obtener un determinado efecto, desdeñando los que resultan desfavorables (sentencias Tribunal de lo Contencioso Administrativo -TCA- ${ }^{\circ}$ 242/2007, en Revista Tributaria cit., 202, pp. 83 y ss.; y n ${ }^{\circ} 442 / 2017$, en Revista Tributaria cit., 270, pp. 503 y ss.), o aplicar el derecho a una forma previamente desestimada (Sent. TCA, n 565/2012 de 13/09/2012, en Revista Tributaria cit., 242, p. 927 ).

No obstante, la invocación por el contribuyente ha sido cuestionada por la Dirección General Impositiva (DGI), en Consultas 4.225/2002, 4.050/2004 y 5.423/2012, con el apoyo de BERGSTEIN (2008), quien aporta el fundamento de la regla del acto propio (pp. 3842). A nuestro criterio, dicha regla no puede invocarse en materia de reserva legal, que escapa a la disposición de las partes, ni en contra del derecho a rectificar las declaraciones en caso de error de hecho o de derecho (art. 64 CT).

9.3 La calificación es una actividad sometida a legalidad, que no admite discrecionalidad (TAVEIRA (2008), p. 184), por lo que la Administración no puede invocar este principio solo porque recaudaría más, ni el contribuyente por la única razón de que la forma elegida lo llevó a pagar más impuestos.

La libertad que posee el legislador para la calificación jurídica de las situaciones y actos, no se extiende al intérprete (TAVEIRA (2008), p. 61), que -salvo que las normas tributarias dispongan otra cosa- debe atenerse al derecho privado para determinar la adecuación de las formas utilizadas por los particulares (FAGET, 1993, p. 206 y sentencia TCA n ${ }^{\circ}$ $565 / 2012$ cit.), otorgando prioridad al contenido, que es el resultado de la función del negocio determinada por su estructura (GAMARRA, 1967, p. 126), y no de la apariencia del mismo o de la calificación que hayan realizado las partes (GAMARRA, 1977, p. 196). 9.4 La inadecuación de la forma comprende los casos de simulación y error. SEIJAS \& WHITELAW (2002) incluyen también la ocultación, que definen como la no exteriorización del negocio existente (pp. 466 y 468). No obstante, si la ocultación consiste en hechos, no puede hablarse de inadecuación, desde que la forma de los mismos no es tomada en cuenta por el Derecho (DE BARROS, 2014, p. 94); mientras que si se hubieran 
utilizado actos o negocios ficticios con esa finalidad, estaría subsumida en la simulación. Cuando la forma representa un negocio inexistente o diverso al realizado (distintas hipótesis de simulación ), se prescinde de los elementos ficticios, recalificando los actos de acuerdo con la realidad subyacente.

Si una persona jurídica ha sido parte en tales negocios, lo que decae no es la personería jurídica, sino la forma contractual adoptada (FAGET, 1993, pp. 373 y 383-384), lo que constituye una hipótesis diferente a la del disregard (art. 189 LSC), desde que dicho instituto “...no implica la antinomia ficción-realidad (que sí suponen las formas jurídicas inadecuadas) sino la antinomia oponibilidad-inoponibilidad, lo que implica que la realidad de la personería jurídica no está en juego (aunque sí pueda estar en juego un uso fraudulento de la misma)" (FAGET, 1993, p. 392. El destacado en negrita pertenece al original). El fraude que afecte al acto o al uso de la personería jurídica, sin poner en duda su realidad, no presupone, entonces, una inadecuación de la forma, por lo que no está comprendido en el inc. $2^{\circ}$ del art. $6^{\circ} \mathrm{CT}$. Anteriormente FAGET (1993) incluía al negocio en fraude a la ley como un caso de inadecuación de la forma (pp. 373 y 386), pero luego modificó su opinión sosteniendo que el art. $6^{\circ}$ inc. $2^{\circ} \mathrm{CT}$ es una norma aplicable exclusivamente al caso de inadecuación entre forma y sustancia $-\mathrm{y}$ no una norma antielusiva genérica, que permita considerar configurado el hecho generador que estrictamente no se ha configurado- por lo que cuando la forma jurídica es adecuada, no corresponde la descalificación ni el fraude a la ley (FAGET, 2004, pp. 437-438).

9.5 Por consiguiente, es necesario distinguir en cada caso, si estamos ante una hipótesis de inadecuación de la forma o de un negocio adecuado, utilizado para defraudar al crédito fiscal. Siempre existirán casos dudosos, como es el que se suele citar de los aportes de bienes a una sociedad anónima, con la única finalidad de intercambiar esos bienes entre los aportantes, mediante las adjudicaciones posteriores a la liquidación, obteniendo así un importante ahorro fiscal. En el caso, es claro el fraude (en su acepción de engaño), pero dudosa la vía que corresponde para enfrentar esa situación, porque existen varios negocios y actos encadenados, con intervención de un tercero (la sociedad), por lo que para recalificar la situación de acuerdo con la causa verdadera (art. 1289 CC), es necesario, o bien sostener que la interposición de la sociedad fue ficticia; o bien que, aun siendo verdadera, se realizó en fraude a los derechos del acreedor tributario (art. 189 LSC).

10. Diferencias con la interpretación económica, la interpretación teleológica y las normas antielusivas genéricas.

10.1 Para la "interpretación económica" -originada en Alemania en la Ordenanza Fiscal de 1919 y en la ley de Adaptación Impositiva de 1934- "En la interpretación de las leyes tributarias debe tenerse en consideración el objetivo, el significado económico y la evolu- 
ción de las situaciones de hecho".

Más que un principio de interpretación, se trataba de un método antielusivo para atrapar todo otro negocio o figura jurídica a la que pueda atribuirse un resultado económico análogo al del acto jurídico vinculado al presupuesto de hecho (TAVEIRA, 2008, pp.173-180 y 204-207; TARSITANO, 2004, pp. 443 y ss.).

Este principio tiene su paralelo en el derecho privado en la doctrina de las normas materiales, también originada en Alemania e Italia, compartida por GAMARRA como la más justa (1992, p. 218-221; y 1999, pp. 213-215), planteo que no tiene en cuenta que también hay normas formales, que solo pretenden vedar determinados medios o procedimientos para lograr un resultado económico o material (BLENGIO, 1985, p. 47), y que no pueden existir reglas antielusivas sin ley que las establezca).

En cuanto al método en sí mismo, se señala que no hay hechos jurídicos o económicos puros, sino que lo que existe son cortes de lenguaje; y que en el contexto jurídico solo cabe hablar de elementos juridizados, siendo inadmisible atribuir efectos de derecho a hechos meramente económicos, agregando que la interpretación económica solo existe para los economistas (DE BARROS, 2014, pp. 87-93).

También se ha advertido del peligro que encierra esta regla antielusiva, recordándose que en Alemania se aplicó con finalidad recaudatoria; y que constituye excepción al principio de igualdad de las partes, amenazando a los principios de legalidad y de seguridad jurídica, motivo por el cual algunos países -como Alemania en 1977 y España en 1995- lo han abandonado, en tanto que Argentina lo ha mantenido con reservas, al supeditar su aplicación a la utilización de formas jurídicas inadecuadas (TAVEIRA, 2008, pp. 176-177 y 204-207; TARSITANO, 2004, pp. 444-446).

10.2 La interpretación finalista o teleológica del derecho tributario, reproduce la posición de la "jurisprudencia de intereses", en su debate con la "jurisprudencia de conceptos", al propiciar una interpretación libre, finalista, basada en la idea del Estado social, que se dirige al conocimiento de la realidad en detrimento de la forma, posición criticada por considerarla un pretexto para forzar los límites de la tipicidad (TAVEIRA, 2008, pp. 174 y 181-183), o por comprometer la seguridad o certeza jurídica (BLANCO, 2008, p. 52). En realidad la crítica debe dirigirse, no al método, sino a la aplicación que se hace del mismo, porque si se confunde la ratio legis de la norma con los fines de una rama del Derecho, la interpretación teleológica indefectiblemente conducirá a un resultado extensivo en beneficio del Estado.

En esta materia los principios no deben referirse, entonces, a una especie de finalidad financiera, sino a los elementos de la obligación tributaria establecidos por la ley (TAVEIRA, 2008, pp. 182-184), particularmente al canon constitucional de legalidad y tipicidad, cuyo mensaje se dirige no solo al legislador, sino también a todos los que deben cumplir o hacer cumplir la ley (DE BARROS, 2014, pp. 96-97). 
10.3 En busca de criterios más seguros para el control de los actos fraudulentos, se pasó del modo basado en la interpretación -por integración-, a las reglas generales antielusivas, que, según TAVEIRA (2008), fundan la prevalencia de la sustancia sobre la forma en conceptos como el de "abuso de formas" (Alemania, Austria y Luxemburgo), "abuso de derecho" (Francia) o "fraude a la ley" (España), (pp.199-204). Estas normas no van, entonces, por el lado de la extensión analógica del hecho generador, sino por la recalificación del acto para reconducirlo a la forma prevista en la norma fiscal, que se considera más adecuada .

En el caso del art. del art. 24 LGT, en su versión de 1963, se debatía si el fraude a la ley implicaba el uso de la analogía, pero en realidad no se trataba de extender el hecho generador, sino de la reconducción del negocio celebrado con el propósito de eludir el tributo, a su norma propia (GONZÁLEZ, 1997, p. 245). El art. 15 de la LGT en la versión de 2003, se refiere a la misma situación bajo la denominación de conflicto en la aplicación de la norma tributaria, sistema por el que se aplica la norma que hubiera correspondido a los actos o negocios usuales o propios, cuando los mismos sean notoriamente artificiosos o impropios para la consecución del resultado obtenido y no produzcan efectos jurídicos o económicos relevantes, distintos del ahorro fiscal y de los efectos que se hubieran obtenido con los actos o negocios usuales o propios.

Las reglas antielusivas se aplican a la recalificación de un negocio verdadero y lícito, lo que implica establecer una limitación al ejercicio de la libertad de los particulares de adoptar las formas jurídicas que estimen más favorables para sus intereses, lo que solo puede establecerse por ley (GARCÍA, 2004, p. 479).

Esta es la crítica que le hacemos a la sentencia de GATTO DE SOUZA (Sent. $N^{\circ} 21$ de 28/04/1967, en La Justicia Uruguaya, T. 55, Montevideo, 1967, c. n 6.749), que admitió como gravada por el Impuesto de Herencias una donación indirecta, invocando como fundamento la opinión de JARACH, en el sentido de que al derecho tributario le interesa la relación económica privada y no la forma jurídica. Este argumento supone dar entrada al "principio de la realidad económica" sin ley que lo respalde y en abierta contradicción con el régimen legal entonces imperante (supra nral. 8.).

$10.4 \mathrm{El}$ principio de la realidad del art. $6^{\circ} \mathrm{CT}$, en cambio, no extiende por analogía el hecho generador, ni recalifica un acto o negocio verdadero y lícito, sino que interpreta la norma para determinar si su sentido, más allá de las palabras, alcanza al acto o negocio que tiene la misma sustancia que el hecho imponible.

Por consiguiente, no constituye una amenaza a los principios de legalidad y seguridad jurídica, desde que la recalificación del derecho tributario no difiere en esencia de la que se hace en el derecho privado. Tampoco constituye una excepción al principio de igualdad de las partes, porque ambas pueden invocarlo en su beneficio, permitiendo -ademásasegurar la igualdad entre los contribuyentes (BORDOLLI, 1994, p. 18). La solución de 
los casos que no puedan ser recalificados por el principio de la realidad, corresponde a la ley, y no al intérprete, que carece de autonomía calificadora (TARSITANO, 2004, p. 448; FAGET, 2004, p. 438 y 440; TAVEIRA, 2008, p. 61). En estos casos habrá elusión, y no evasión del tributo. En general se entiende por elusión, el evitar la verificación del hecho generador por medios lícitos, aprovechando los vacíos dejados por la ley; diferenciándose de la economía de opción, que consiste en utilizar las alternativas normales brindadas por el ordenamiento jurídico para la obtención de un ahorro fiscal legítimo; y de la evasión, en la que se utilizan medios ilícitos para ocultar o disimular el hecho generador acaecido. IV. POSIBILIDAD DE UN CONCEPTO DE FRAUDE A LA LEY PROPIO DEL DERECHO TRIBUTARIO.

11.1 El fraude a la ley supone la violación de reglas limitativas del ejercicio de la autonomía privada, por lo que, como toda restricción a libertad, solo puede ser impuesta por ley (art. 10 inc. $2^{\circ}$ de la Constitución). Por consiguiente, no existiendo en nuestro Derecho norma legal alguna que regule el fraude a la ley en materia tributaria, debe aplicarse en subsidio, el derecho privado (art. 14 inc. $2^{\circ} \mathrm{CT}$ ), cuya elaboración sistemática solo comprende a la violación indirecta de normas prohibitivas

La disposición antes citada - a diferencia de lo dispuesto por el art. $5^{\circ}$ inc. $2^{\circ} \mathrm{CT}-$, no faculta al intérprete para la elección de la norma supletoria en casos de vacío, sino que remite -en primer término y sin condicionamiento alguno- al derecho privado.

11.2 No obstante, desde la teoría general del derecho ATIENZA \& MANER0 (2000, "Ilícitos atípicos", citados en BLANCO, 2008, p. 50-52), señalan que el fraude a la ley implica la violación, no de una regla de derecho, sino de un principio jurídico, desde que lo que la dogmática del Derecho Civil y Tributario identifica como el fin o espíritu no son otra cosa que los principios, posición que, entiende BLANCO, nos conduce obligatoriamente al principio de la capacidad contributiva.

11.3 Nuestro derecho consagra el concepto que vincula la ilicitud a la violación de un deber jurídico (mandato o prohibición) (GAMARRA, 1974, pp. 78-79), o sea de normas prohibitivas o imperativas, que solo pueden ser establecidas por la ley; o de un derecho subjetivo (supra nral. 6.2), lo que excluye que pueda haber ilicitud por violación de principios no llevados a la norma, sea en forma directa o por vía de integración.

En materia de obligación tributaria, la integración es un mecanismo que se utiliza en ausencia de las normas fiscales (que incluyen al derecho privado, en los casos de remisión expresa o subsidio), y no en lugar de ellas, sin perjuicio de que en materia de la existencia y cuantía de los tributos no existen vacíos, estando prohibido al intérprete recurrir a la integración analógica (art. 5 inc. $1^{\circ} \mathrm{CT}$ ).

Si bien los arts. 5, 6 y 14 CT reconocen la autonomía del derecho tributario material, la misma encuentra sus límites en el mantenimiento de la seguridad jurídica y la unidad del Derecho. 


\section{CONSECUENCIAS DE LOS ACTOS QUE ESCAPAN A LA LETRA DE LA LEY, PERO NO A SU SENTIDO.}

12.1 En definitiva, el intérprete solo puede llegar hasta el límite de la interpretación extensiva (art. $4^{\circ} \mathrm{CT}$ ) -que no extiende el sentido de la norma, sino de los vocablos impropiamente utilizados por el legislador (VALDÉS, 1996, pp. 270-271; TAVEIRA, 2008, p. 190) - estándole vedada tanto la integración analógica, como la recalificación de un negocio lícito y adecuado a la realidad para llevarlo al hecho generador, por lo que los vacíos de la norma deben ser colmados por la ley, a la que pertenece la autonomía calificadora del derecho tributario.

12.2 Por consiguiente, en la situación en que el acto está alcanzado por el sentido de la norma fiscal, aunque no por sus palabras, lo que se pretende con el mismo es el escape de la obligación tributaria, y no del hecho generador. En este caso, se verifica el hecho generador en forma velada, al igual que en la simulación, aunque ello se oculta o disimula, no a través de un negocio meramente aparente o diverso al realmente celebrado, sino mediante la realización de un negocio verdadero, pero de manera artificiosa o anómala. Con las normas antielusivas, en cambio, el hecho generador no se verifica, pero igualmente el acto es alcanzado por la extensión analógica de la norma fiscal o por su reconducción a una forma gravada, que se considera más adecuada.

13. En el caso del acto o negocio que escapa a la letra de la ley que establece el hecho generador, pero no a su sentido, no existe en realidad violación de una norma, no solo por lo dicho supra nral. 6.4, sino porque con el acto se verifican los hechos y situaciones previstos en la misma como hipótesis de incidencia. En cambio, cuando se trata de una prohibición, la consecuencia será la nulidad, salvo disposición legal en contrario, y, como en el caso anterior, la aplicación de la norma que se pretendía eludir.

\section{BIBLIOGRAFÍA CONSULTADA}

BLANCO, A. (2008). "Fraude e ilícitos tributarios en el derecho uruguayo actual". En MALET VÁZQUEZ, M. y SILVA FORNÉ, D. (Coordinadores), Derecho Penal, Hacienda y Administración Pública, Montevideo, FCU.

BLANCO, A. (2013). Estudios críticos sobre finanzas públicas y derecho tributario, Montevideo, FCU.

BLENGIO, J. E. (1985). "El negocio en fraude a la ley". En Anuario de Derecho Civil 
Uruguayo, T. XV, Montevideo, FCU.

BORDOLLI, J. C. (1994). "El principio de la realidad y la jurisprudencia del Tribunal de lo Contencioso Administrativo", en Revista Tributaria IUET, T. XXI, (118).

CARNELLI, S. (2012). "Causa del Contrato - Análisis de la nueva doctrina de Gamarra sobre la causa del contrato". En Anuario de Derecho Civil Uruguayo, T. XLII, Montevideo, FCU.

DE BARROS CARVALHO, P. (2014). "Entre la forma y el contenido: crítica a la interpretación económica de los hechos jurídicos”. En Revista de Derecho UCUDAL, 2a época, año 9, (9), Montevideo.

FAGET PRATI, A. (1981). "La forma jurídica inadecuada y el fraude a la ley fiscal". En Revista Tributaria IUET T. VIII, (42).

FAGET PRATI, A. (1993). “El «Disregard of legal entity» en el Derecho Tributario". En Revista Tributaria IUET., T. XX, (116).

FAGET PRATI, A. (2004). “Interpretación y calificación en materia tributaria. Las formas jurídicas inadecuadas y el fraude a la ley fiscal". En Revista Tributaria IUET., T. XXXI, (181).

FERRARI REY, M. \& GUTIÉRREZ PRIETO, G. (2011). Conjuntos Económicos enfoque tributario. Montevideo, AMF-ORT, 2011.

GAMARRA, J. (1992). Tratado de Derecho Civil Uruguayo, T. VI, reimpresión de la $3^{\text {a }}$ ed., Montevideo, FCU.

GAMARRA, J. (1967). Tratado de derecho civil uruguayo, T. VIII, Montevideo, AMF.

GAMARRA, J. (1999). Tratado de derecho civil uruguayo, T. XIII, Montevideo, FCU, $3^{\text {a }}$ ed., ed. Electrónica de IMPO.

GAMARRA, J. (1972). Tratado de derecho civil uruguayo, T. XIV, Montevideo.

GAMARRA, J. (1974). Tratado de derecho civil uruguayo, T. XVI, Montevideo.

GAMARRA, J. (1977). Tratado de derecho civil uruguayo, T. XVIII, Montevideo.

GAMARRA, J. (2009). Tratado de derecho civil uruguayo, T. XXVI. Montevideo, FCU. GARCÍA NOVOA, C. (2004). "Las medidas para combatir la elusión fiscal. Cláusulas generales y especiales". En Revista Tributaria IUET, T. XXXI, (181).

GARCÍA NOVOA, C. (2008). Prólogo a TAVEIRA TORRES, H. (2008), Derecho tributario y Derecho privado, Argentina, Marcial Pons Argentina.

GONZÁLEZ GARCÍA, E. (1997). “Interpretación de la norma jurídica tributaria”. En Lecciones y Ensayos, (67/68), Buenos Aires, Abeledo-Perrot.

HESSDÖRFER, A. (2014). "Fraude a la ley tributaria; un problema no resuelto por el «principio de la realidad»". En Revista Tributaria IUET, T. XLI, (241).

SÁNCHEZ FONTÁNS, J. (1965). “Análisis general de la ley". En La Ley de Alquileres de 1964: comentarios, antecedentes y documentos, texto legal anotado y concordado, Montevideo, FDCS. 
SEIJAS, A. \& WHITELAW, J. (2002). “Forma y sustancia en la ley tributaria". En Revista Tributaria IUET, T. XXIX, n 169.

TARSITANO, A. (2004). "Interpretación de la ley tributaria”. En Revista Tributaria IUET, T. XXXI, n ${ }^{\circ} 181$.

TAVEIRA TORRES, H. (2008). Derecho tributario y Derecho privado, Argentina, Marcial Pons Argentina.

VALDÉS COSTA, R. (1996). Curso de Derecho Tributario, 2a ed., Bogotá, Editorial Temis.

VALDÉS COSTA, R., VALDÉS de BLENGIO, N. \& SAYAGUÉS ARECO, E. (2002). Código Tributario de la República Oriental del Uruguay, comentado y concordado, $5^{\mathrm{a}}$ ed., actualizada por VALDÉS de BLENGIO, N. Montevideo, FCU.

Fecha de recepción: 4 mayo 2020.

Fecha de aceptación: 22 junio 2020. 